\title{
Family Physicians' Satisfaction with Current Practice: What Is the Role of Their Interactions with Specialists?
}

\section{Satisfaction des médecins de famille face à la pratique actuelle : quel est le rôle de leur interaction avec les spécialistes?}

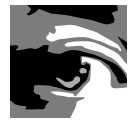

by AMARDEEP THIND, MD, PHD

Associate Professor, Department of Family Medicine and Department of Epidemiology and Biostatistics

Schulich School of Medicine and Dentistry

University of Western Ontario London, ON

TOM FREEMAN, MD, MCLSC

Professor and Head, Department of Family Medicine

Schulich School of Medicine and Dentistry

University of Western Ontario London, ON

CATHY THORPE, MA

Research Associate, Department of Family Medicine

Schulich School of Medicine and Dentistry

University of Western Ontario

London, ON 
Amardeep Thind et al.

ANDREA BURT, MA

Research Assistant, Department of Family Medicine

Schulich School of Medicine and Dentistry

University of Western Ontario

London, $\mathrm{ON}$

MOIRA STEWART, PHD

Professor, Department of Family Medicine

Schulich School of Medicine and Dentistry

University of Western Ontario

London, ON

\begin{abstract}
Provision of high-quality care sometimes necessitates a referral to, and receipt of timely feedback from, specialist physicians. Interaction with specialists is a key role of family physicians, but it has not received significant attention with respect to its impact on family physician satisfaction. The authors conducted a cross-sectional analysis of data gathered from a decennial census of family physicians in southwestern Ontario. The conceptual framework was based on the model developed by the Society of General Internal Medicine (SGIM) Career Satisfaction Work Group. More than two-thirds of respondents were "very satisfied" with their current practice. Stepwise regression analysis based on a generalized linear model showed that greater difficulty in referring patients to specialists was associated with $23 \%$ lower odds of being "very satisfied". Not receiving a timely response from specialists was associated with $26 \%$ higher odds of not being "very satisfied." Marital status, teaching involvement and practice volume were also associated with satisfaction. The findings indicate that the practice of family medicine offers a fulfilling career in today's medical marketplace. However, linkages and feedback between family physicians and specialists need to be augmented.
\end{abstract}

\title{
Résumé
}

Pour fournir des soins de haute qualité il est parfois nécessaire de diriger le patient vers un spécialiste et de recevoir de ce dernier une rétroaction en temps opportun. Linteraction avec les spécialistes joue un rôle important dans le travail du médecin de famille, toutefois cette question na pas reçu toute l'attention nécessaire pour ce qui est de son impact sur la satisfaction du médecin de famille. Les auteurs ont effectué une analyse transversale des données recueillies à partir d'un recensement décennal mené auprès des médecins de famille dans le sud-ouest ontarien. Le cadre conceptuel repo sait sur le modèle élaboré par un groupe de travail de la SGIM (Society of General Internal Medicine). Plus des deux tiers des répondants ont dit être « très satisfait » avec leur pratique. Une analyse de régression par degrés effectuée en utilisant des modèles linéaires généralisés a démontré qu'une difficulté accrue à diriger les patients 
vers un spécialiste diminue de 23 pour cent la probabilité de se montrer « très satisfait ». Pour sa part, l'absence de réponse en temps opportun augmente de 26 pour cent la probabilité de ne pas se montrer «très satisfait ». L'état civil, l'enseignement et le volume de la pratique sont aussi associés à un degré de satisfaction. Les résultats corroborent l'idée que la médecine familiale offre une carrière pleine ment satisfaisante dans le marché actuel de la médecine. Toutefois, il est nécessaire d’accroître les échanges et la rétroaction entre les médecins de famille et les spécialistes.

\section{$\mathrm{F}$} AMily physicians play a Key role in healthCARE Delivery in CANAdA's healthcare system, where they are the point of first contact and act as their patients' navigators and advocates in a complex system. Given the evidence linking physician satisfaction to key patient outcomes, it is vital to understand its determinants. For example, literature suggests that inappropriate prescribing patterns, poor patient adherence to medications, increased patient turnover and patient satisfaction are related to physician satisfaction (DeVoe et al. 2007; DiMatteo et al. 1993; Grol et al. 1985; Kerse et al. 2004).

Satisfaction can also play an important role in practitioners' entry into and exit from the workforce. There is evidence to suggest that Canadian physicians suffer from career stress and burnout, and these factors have been linked to future relocation intentions (Martin 1999; Thommasen et al. 2001). Data from the United States suggest that recruiting and replacing a primary care physician costs approximately a quarter of a million dollars (Buchbinder et al. 1999). Satisfaction with practice may play a key role in recruiting more students to undertake medicine as a career. Recruitment and retention have major implications for the future family physician workforce, as data from the Canadian Resident Matching Service (CaRMS) indicate that the percentage of medical school graduates choosing family medicine as a career choice has hovered around 30\% in the past decade (CaRMS 2003; MacKean and Gutkin 2003).

Provision of high-quality patient care sometimes necessitates a referral to, and receipt of timely feedback from, specialist physicians. Interaction with specialists is a key role that family physicians play in the system, but it has not received significant attention with respect to its impact on family physician satisfaction. Many studies have examined the role of physician socio-demographic and practice characteristics in predicting satisfaction, but there is a paucity of literature on the role of interactions with specialists as a determinant of satisfaction.

We used data from a decennial census of all family physicians in southwestern Ontario to understand the role of making specialist referrals and receiving timely response from specialists in predicting family physicians' satisfaction with their current practice. 
FIGURE 1. Model of family physician satisfaction with current practice

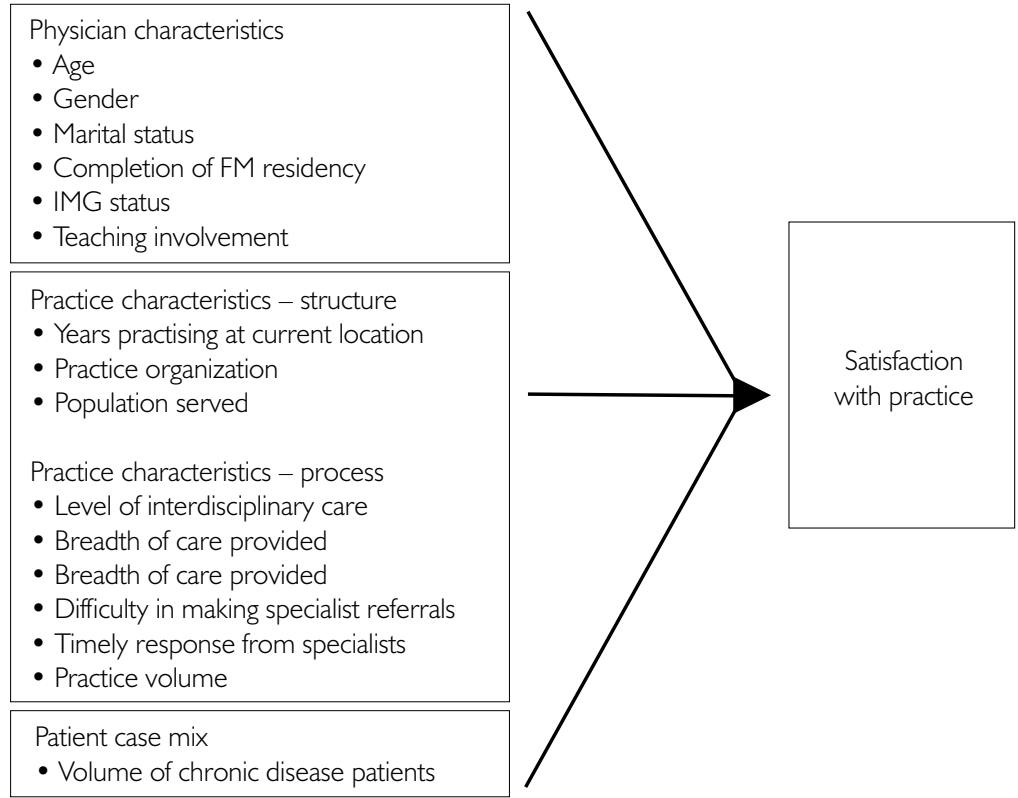

\section{Methods}

Conceptual model

Figure 1 depicts the conceptual framework underlying our analyses, and is derived from the work of the Society for General Internal Medicine (SGIM) Career Satisfaction Work Group (Williams et al. 2002). Satisfaction with practice is postulated to be dependent on physician socio-demographics, practice characteristics and the patient case mix.

Physician socio-demographic characteristics that may influence satisfaction include age and gender, marital status, completion of family medicine residency, international medical graduate (IMG) status and involvement in teaching (Keeton et al. 2007; Rivet et al. 2007). Literature suggests that older physicians are more satisfied with their practice, and that female physicians may be more satisfied than their male counterparts (Rivet et al. 2007; Whalley et al. 2006). IMGs face unique challenges in practising medicine in a country not their own, and this may have a differential impact on their satisfaction (Leigh et al. 2002). Marital status and teaching involvement may provide support and a refuge from the inherently stressful nature of clinical practice; and completion of a family medicine residency may impart additional skills to enable physicians to deal with day-to-day practice challenges, thus affecting their satisfaction.

Practice characteristics can be defined in terms of structure or process. The number of years practising at the current location, practice organization and patient population served have been shown to affect satisfaction (Grembowski et al. 2003; 
Williams et al. 2002). The environment within the practice, as captured by process variables such as level of interdisciplinary care and breadth of care provided, may positively affect satisfaction by enabling provision of higher-quality patient care within the practice itself. A high volume of patients, on the other hand, may have a negative impact on physician satisfaction, as it may not be conducive to the provision of good-quality care; it may also reflect a loss of control over surroundings (Keeton et al. 2007). Difficulty in making specialist referrals and lack of timely response from specialists are postulated to lead to poorer satisfaction because they impede the provision of high-quality patient care (Grembowski et al. 2003). Lastly, patient mix has been shown to be associated with physician satisfaction (Williams et al. 2002).

\section{Study design and data source}

We conducted a cross-sectional analysis of data gathered from family physicians in southwestern Ontario. The data were collected as part of a decennial census of all family physicians in the 10 counties surrounding and including London, and investigated a broad range of physician, practice and health system characteristics. In the Fall of 2004, the survey was mailed to all 1,044 family physicians in southwestern Ontario using a modified Dillman method (Dillman and Dillman 2000). The initial package, sent by registered mail with recorded delivery, included the survey, an information letter, a $\$ 25$ gift certificate and a self-addressed stamped envelope. Reminder postcards were sent to all physicians two weeks later. Two additional surveys were mailed to non-responders, the first approximately four weeks after the initial mailing and the second about four weeks after that. The response rate was $70.0 \%(n=731)$. Survey responders and non-responders were similar with respect to age, gender and rural/ urban status (Table 1).

TABLE 1. Comparison of survey respondents and non-respondents

\begin{tabular}{|c|l|l|l|}
\hline \multicolumn{2}{|l|}{ Survey respondents } & Non-respondents & p-value \\
\hline Age (mean) & 48.4 years & 49.8 years & 0.07 \\
\hline Gender & \multicolumn{2}{l|}{} \\
\hline Male & $68.9 \%$ & $72.2 \%$ & 0.33 \\
\hline Female & $31.1 \%$ & $27.8 \%$ & \\
\hline Location & \multicolumn{2}{|l}{} \\
\hline Urban & $91.8 \%$ & $93.0 \%$ & 0.60 \\
\hline Rural & $8.2 \%$ & $7.0 \%$ & \\
\hline
\end{tabular}




\section{Variable specification}

The dependent variable was based on the response to the question "How satisfied are you with your current practice?" Response categories were presented on a Likert scale ( 1 = "not at all" to 5 = "very satisfied"); based on the frequency distribution, we dichotomized the responses to "very satisfied" (response category 5 ) and "not very satisfied" (response categories 1-4) (Grembowski et al. 2003; Hadley and Mitchell 2002; Leigh et al. 2002). The dependent variable was coded as a dichotomous variable because the responses were not normally distributed, and because of the assumption that physicians are (or should be) very satisfied, an approach that is consistent with prior research (Grumbach et al. 1998; Hadley and Mitchell 1997; Stoddard et al. 2001).

Among the independent variables, physician age was continuous; marital status, completion of family medicine residency, IMG status and teaching activities (involved in undergraduate or postgraduate teaching or not) were dichotomous. Structural practice characteristics were captured using the following variables: years practising at current location, population served (urban, suburban, inner city; small town; or rural and isolated) and whether or not the practice was mainly funded through fee-forservice (FFS) payments (Stoddard et al. 2001). ${ }^{1}$

Practice characteristics capturing the process of care included level of interdisciplinary care, breadth of care provided, usual number of patients seen per week $(\leq 100$, $101-150$ or $>150$ ), difficulty in referring patients to specialists and timely response from specialists. Interdisciplinary care was a continuous variable and was constructed by summing the responses to the question "Indicate the types of healthcare providers with whom you share patient care within your main patient care setting" ${ }^{\prime \prime}$; breadth of care was similarly constructed by summing responses to the question "Thinking about your main patient care setting, which of the following procedures do you perform?"3 Difficulty in referring patients to specialists was based on the questions "How difficult is it for you to refer patients to specialists?"; responses were presented on a Likert scale ( 1 = "not difficult at all" and $5=$ "very difficult") and were entered as continuous variables, with a higher score indicating greater difficulty (Grembowski et al. 2003; Stoddard et al. 2001). Timely response from specialists was based on the question "How timely a response do you receive from specialists after they have seen your patients?"; responses were again presented on a Likert scale (coded as $1=$ "very timely" and $5=$ "not timely at all") and were entered as continuous variables, with a high score indicating greater difficulty (Grembowski et al. 2003). Patient case mix was based on the response to a question asking the percentage of patients seen per week for reasons of chronic disease.

\section{Data analysis}

Data analysis was carried out using Stata/SE Version 10 (Statacorp 2007). The unit 
of analysis was the individual physician. Bivariate relationships between the outcome and independent variables were assessed using the chi-square and Student's t-tests for categorical and continuous data, respectively. In order to ensure parsimony, a p-value of $<0.2$ was used to select variables for inclusion in the regression model. Using a generalized linear model with a logit link and a binomial distribution, a stepwise regression analysis was conducted. A parsimonious model was produced by backward stepwise regression, dropping variables with $p$-values $>0.05$. Collinearity was assessed and not found to be a problem. Sensitivity analyses were conducted by using a continuous dependent variable, i.e., the actual scores ( 1 to 5 ) on the Likert scale; because the results were identical, we present the odds ratios from the most parsimonious model.

\section{Results}

Table 2 presents the bivariate relationships between the outcome and the independent variables. Slightly more than two-thirds ( $\mathrm{n}=495,69 \%)$ of family physicians in our sample said they were "very satisfied" with their current practice.

TABLE 2. Characteristics of family physicians reporting "very satisfied" vs. "not very satisfied" ( $n=7 \mid 9)$

\begin{tabular}{|c|c|c|c|}
\hline & $\begin{array}{l}\text { Not very satisfied } \\
\qquad(n=224)\end{array}$ & $\begin{array}{l}\text { Very satisfied } \\
\quad(n=495)\end{array}$ & p-value \\
\hline \multicolumn{4}{|c|}{ Physician characteristics } \\
\hline Age & $50^{\mathrm{a}}$ & $48.9^{\mathrm{a}}$ & 0.211 \\
\hline \multicolumn{4}{|l|}{ Gender } \\
\hline Male & $31.8 \%$ & $68.2 \%$ & 0.57 \\
\hline Female & $29.7 \%$ & $70.3 \%$ & \\
\hline \multicolumn{4}{|c|}{ Married/Partnered } \\
\hline No & $45.5 \%$ & $54.5 \%$ & 0.009 \\
\hline Yes & $29.8 \%$ & $70.2 \%$ & \\
\hline \multicolumn{4}{|c|}{ Completed FM residency } \\
\hline No & $35.5 \%$ & $64.5 \%$ & 0.022 \\
\hline Yes & $27.5 \%$ & $72.5 \%$ & \\
\hline \multicolumn{4}{|c|}{ International medical graduate } \\
\hline No & $30.2 \%$ & $69.8 \%$ & 0.716 \\
\hline Yes & $32 \%$ & $68 \%$ & \\
\hline Teaching & & & \\
\hline
\end{tabular}


TABLE 2. Continued

\begin{tabular}{|c|c|c|c|}
\hline No & $37.6 \%$ & $62.4 \%$ & 0.000 \\
\hline Yes & $18.5 \%$ & $81.5 \%$ & \\
\hline \multicolumn{4}{|l|}{ Practice characteristics - structure } \\
\hline Years practising at current location & $17.7^{\mathrm{a}}$ & $12.7^{\mathrm{a}}$ & 0.223 \\
\hline \multicolumn{4}{|l|}{ Practice organized as FFS } \\
\hline No & $27.2 \%$ & $72.8 \%$ & 0.415 \\
\hline Yes & $32 \%$ & $68 \%$ & \\
\hline \multicolumn{4}{|l|}{ Population served } \\
\hline Urban, suburban, inner city & $34.7 \%$ & $65.3 \%$ & 0.176 \\
\hline Small town & $26.6 \%$ & $73.4 \%$ & \\
\hline Rural and isolated & $32.2 \%$ & $67.8 \%$ & \\
\hline \multicolumn{4}{|l|}{ Practice characteristics - process } \\
\hline Level of interdisciplinary care & $2.8^{\mathrm{a}}$ & $3.3^{\mathrm{a}}$ & 0.038 \\
\hline \multicolumn{4}{|l|}{ Usual no. of patients seen per week } \\
\hline$\leq 100$ & $24 \%$ & $76 \%$ & 0.005 \\
\hline $10|-| 50$ & $37.3 \%$ & $62.7 \%$ & \\
\hline$>150$ & $34.6 \%$ & $68.4 \%$ & \\
\hline Breadth of care provided & $6.8^{\mathrm{a}}$ & $6.5^{\mathrm{a}}$ & 0.307 \\
\hline Difficulty in referring to specialists & $3.4^{\mathrm{a}}$ & $2.9^{a}$ & 0.000 \\
\hline Timely response from specialists & $3.1^{\mathrm{a}}$ & $2.9^{a}$ & 0.000 \\
\hline \multicolumn{4}{|l|}{ Patient case mix } \\
\hline Chronic disease patients as \% of workload & $42.8^{\mathrm{a}}$ & $40.3^{\mathrm{a}}$ & 0.176 \\
\hline
\end{tabular}

a Denotes mean

Among physician characteristics, being married/partnered, having completed a family medicine residency and involvement in undergraduate or postgraduate teaching were significantly associated with being "very satisfied" with current practice. No statistically significant associations were noted between any of the three structural practice characteristics (years practising at current location, whether the practice was FFS or not and population served) and physician satisfaction. 
Among the process-based practice characteristics, physicians working in practices providing more interdisciplinary care were more likely to be "very satisfied" with their current practice, as were physicians who saw fewer patients per week. Greater difficulty in referring patients to specialists was associated with lower satisfaction, as was difficulty in getting a timely response from specialists.

Variables that were significant at the $\mathrm{p}<0.2$ level were entered into the stepwise regression model. Table 3 presents the results of the backward elimination model. Family physicians who were married/partnered had more than twice the odds of being "very satisfied" with their current practice; a similar effect size was noted for family physicians involved in undergraduate or postgraduate teaching - their odds of being "very satisfied" were more than twice those of family physicians not involved in teaching. Family physicians seeing 101-150 patients per week were less likely to be "very satisfied" compared to those seeing fewer than 100 patients per week. Family physicians' satisfaction decreases as difficulty in referring patients to specialists increases and as the timeliness of specialists' responses decreases.

TABLE 3. Stepwise generalized linear model (GLM) regression results of determinants of family physician satisfaction with practice $(n=620)$

\begin{tabular}{|c|c|c|}
\hline & Odds ratio & p-value \\
\hline \multicolumn{3}{|l|}{ Physician characteristics } \\
\hline \multicolumn{3}{|l|}{ Married/Partnered } \\
\hline No & - & - \\
\hline Yes & 2.22 & 0.007 \\
\hline \multicolumn{3}{|l|}{ Teaching } \\
\hline No & - & - \\
\hline Yes & 2.59 & 0.000 \\
\hline \multicolumn{3}{|c|}{ Practice characteristics - process } \\
\hline \multicolumn{3}{|l|}{ Usual no. of patients seen per week } \\
\hline$\leq 100$ & - & - \\
\hline $101-150$ & 0.67 & 0.035 \\
\hline$>150$ & 0.79 & 0.30 \\
\hline Difficulty in referring to specialists & 0.77 & 0.001 \\
\hline Timely response from specialists & 0.79 & 0.014 \\
\hline
\end{tabular}




\section{Discussion}

It is heartening to note that more than two out of every three family physicians in our sample said they were "very satisfied" with their current practice. These numbers are higher than those reported in the National Physician Survey (NPS) 2007, in which only $27 \%$ of interviewed family physicians reported being "very satisfied" with their current professional life. However, if one adds the "very satisfied" (27\%) and "somewhat satisfied" (48\%) response categories of the NPS 2007, the resulting rate is very similar to that of our survey. Differences between the NPS and our survey results could be due to the slightly different wording of the question (NPS: "satisfaction with current professional life"; our survey: "satisfaction with current practice").

Irrespective of the caveats, these numbers attest to the fact that the practice of family medicine offers a fulfilling career in today's medical marketplace. These data can be used in efforts to increase the proportion of medical school graduates opting for family medicine residencies in the CaRMS match (vide supra).

The practice of medicine today is increasingly characterized by a team-based approach, both within and outside the confines of a family practice. A crucial linkage in this approach is the two-way communication between the team members within a family practice and outside providers (e.g., specialists), as would occur when a family physician makes a referral to a specialist and then awaits the specialist's opinion and recommendations. Our findings - that difficulty in referring patients to specialists, and lack of timely response, have a negative impact on family physician satisfaction - should be examined in this light. Both these factors may impede provision of optimal patient care and can be seen as impediments to the professional autonomy of the family physician, thus adversely affecting professional satisfaction (DeVoe et al. 2002; Williams et al. 2002). In an analysis of family physicians practising in the Seattle area, Grembowski and colleagues (2003) found that ease of referral in the context of managed care was associated with greater job and referral satisfaction, and they posit that this could be a proxy for an office that manages patient flow well. Other literature suggests that constraints on the provision of medical care provision or the inability to obtain services for patients can lead to lower physician satisfaction (Landon et al. 2003; Rivet et al. 2007; Stoddard et al. 2001).

Our analyses do not allow us to tease out the causal mechanisms of this interaction. In an analysis of barriers to older cancer patients' being referred to oncologists, Townsley and colleagues (2003) found that the most commonly cited difficulties by primary care physicians making oncologist referrals were length of waiting lists, the oncologists' desire to have a tissue diagnosis before referral and the belief that oncologists seldom relate to primary care physicians. Although there is evidence to show that wait times for particular specialist visits or procedures are a problem (Esmail et al. 2006), other explanations are possible. For example, there could be a relative paucity 
of specialists in southwestern Ontario, or specialists might require specific procedures to be followed prior to accepting a referral, increasing the "hassle factor" for the family physician. Similarly, obtaining a timely response from a specialist may depend on the tests or procedures that he or she wants done, which could be affected by the waiting times for such tests or procedures.

Assuming that our findings are replicated in other studies, policies that encourage development of greater family physician-specialist interaction on a personal level may help to improve satisfaction with consultations and result in more appropriate referrals. Common referral forms that are developed with both family physician and specialist input may expedite the transmission of all relevant information and improve consultations as well. Continued support is required for the addoption of electronic medical records by family practices and for systems to support electronic communication between family physicians and specialists.

Other factors affecting satisfaction included marital status, teaching activities and volume of patients seen per week, findings that are consonant with the literature. Being married/partnered may provide additional support and a refuge from the dayto-day stresses of a busy practice, and involvement in undergraduate or postgraduate teaching may provide a reward or satisfaction in terms of educating the physicians of tomorrow (Eliason et al. 2000; Rivet et al. 2007). A low practice volume was positively associated with satisfaction and could be due to the fact that this allows family physicians to have greater control over their day, and ensure that adequate time is available for patient encounters (Keeton et al. 2007; Stoddard et al. 2001; Whalley et al. 2006).

Our analysis includes some distinct strengths and weaknesses. A major strength is our response rate of $70 \%$, which is higher than the rates of $50 \%-60 \%$ in other physician surveys reported in the literature (Asch et al. 1997; Bovier and Perneger 2003; Linzer et al. 2000; Pathman et al. 2002). Our survey was a census of all family physicians in southwestern Ontario, and there were no statistically significant differences between the responders and non-responders. In addition, we used a conceptual model that has been validated and widely used in the literature, and we controlled for most of the variables identified in the literature.

The caveats that should be borne in mind include the fact that our analysis was cross-sectional in nature, thus precluding any assertions about causality. Because the data were based on physician self-report, there is the possibility that physicians could have erred in reporting on variables such as the number of patients seen per week and patient case mix. Finally, the data are limited in that some variables of interest were not available. For example, physician income and balance between personal and professional commitments have been shown to be significant predictors of physician satisfaction but are unavailable in our data set (Keeton et al. 2007; Landon et al. 2003; Pathman et al. 1996; Rivet et al. 2007). 
In conclusion, our research demonstrates that a majority of family physicians practising in southwestern Ontario are "very satisfied" with their current practice, and that marital status, teaching involvement, practice volume, difficulty in specialist referrals and lack of timely specialist response are significant determinants of their satisfaction level. However, further research is needed to elucidate the causal mechanisms and to generalize these results beyond southwestern Ontario.

\section{ACKNOWLEDGEMENTS}

This study was funded by a grant awarded by the Ontario Ministry of Health and Long-Term Care to the Thames Valley Family Practice Research Unit located at the Centre for Studies in Family Medicine, Department of Family Medicine, Schulich School of Medicine and Dentistry, University of Western Ontario. Dr. Amardeep Thind acknowledges support from the Canada Research Chairs Program. Dr. Moira Stewart acknowledges funding support of the Dr. Brian W. Gilbert Canada Research Chair in Primary Health Care. The views expressed in this paper are the authors' views and do not necessarily reflect those of the Ministry of Health and Long-Term Care. Correspondence may be directed to: Dr. Amardeep Thind, Centre for Studies in Family Medicine, University of Western Ontario, 245 - 100 Collip Circle, London, ON N6G 4X8; tel.: 519-8585028; fax: 519-858-5029; e-mail: athind2@uwo.ca.

NOTES

1. Physicians practising in Family Health Groups (FHGs) were categorized as being funded predominantly through fee-for-service (FFS) payments; those practising in Family Health Networks (FHNs), Community Health Centres (CHCs), Health Service Organizations (HSOs) or other practice models were categorized as non-FFS.

2. Responses to this question could include family physicians, specialist physicians, nurse practitioners, nurses, dieticians/nutritionists, psychologists, occupational therapists, physiotherapists, social workers, case workers, pharmacists and midwives.

3. Response options included excision of skin lesions, electrocautery of skin lesions, aspiration of breast cysts, incision and drainage, drainage of thrombosed hemorrhoids, ingrown toenail excision, IUD insertion, sigmoidoscopy, joint aspiration, endometrial biopsy, casting/splinting and suturing.

\section{REFERENCES}

Asch, D.A., M.K. Jedrziewski and N.A. Christakis. 1997."Response Rates to Mail Surveys Published in Medical Journals." Journal of Clinical Epidemiology 50(10): 1129-36. 
Family Physicians' Satisfaction with Current Practice:

What Is the Role of Their Interactions with Specialists?

Bovier, P.A. and T.V. Perneger. 2003. "Predictors of Work Satisfaction among Physicians." European Journal of Public Health 13(4): 299-305.

Buchbinder, S.B., M. Wilson, C.F. Melick and N.R. Powe. 1999. "Estimates of Costs of Primary Care Physician Turnover." American Journal of Managed Care 5(11): 1431-38.

Canadian Resident Matching Service (CaRMS). 2003. Operations Reports E Statistics $-R-1$

Match Reports - 2003. "Table IX: History of Family Medicine as the Career Choice of Canadian Graduates." Retrieved December 13, 2008. <http://www.carms.ca/eng/operations_R1reports_ 03_e.shtml\#table9>.

DeVoe, J., G.E. Fryer Jr, J.L. Hargraves, R.L. Phillips and L.A. Green. 2002. “Does Career Dissatisfaction Affect the Ability of Family Physicians to Deliver High-Quality Patient Care?" Journal of Family Practice 51(3): 223-28.

DeVoe, J., G.E. Fryer Jr., A. Straub, J. McCann and G. Fairbrother. 2007. “Congruent Satisfaction: Is There Geographic Correlation between Patient and Physician Satisfaction?" Medical Care 45(1): 88-94.

Dillman, D. and D. Dillman. 2000. Mail and Internet Surveys: The Tailored Design Method (2nd ed.). New York: Wiley.

DiMatteo, M.R., C.D. Sherbourne, R.D. Hays, L. Ordway, R.L. Kravitz, E.A. McGlynn et al. 1993. "Physicians' Characteristics Influence Patients' Adherence to Medical Treatment: Results from the Medical Outcomes Study." Health Psychology 12(2): 93-102.

Eliason, B.C., C. Guse and M.S. Gottlieb. 2000. "Personal Values of Family Physicians, Practice Satisfaction and Service to the Underserved." Archives of Family Medicine 9(3): 228-32.

Esmail, N., M. Walker and D. Wrona. 2006. Waiting Your Turn: Hospital Waiting Lists In Canada (16th ed.). Vancouver: Fraser Institute.

Grembowski, D., C.M. Ulrich, D. Paschane, P. Diehr, W. Katon, D. Martin, D.L. Patrick and C. Velicer. 2003. "Managed Care and Primary Physician Satisfaction." Journal of the American Board of Family Practice 16(5): 383-93.

Grol, R., H. Mokkink, J. van Eijk, M. Beek, P. Mesker and J. Mesker-Niesten. 1985. "Work Satisfaction of General Practitioners and the Quality of Patient Care." Family Practice 2(3): 12835.

Grumbach, K., D. Osmond, K. Vranizan, D. Jaffe and A.B. Bindman. 1998. "Primary Care Physicians' Experience of Financial Incentives in Managed-Care Systems." New England Journal of Medicine 339(21): 1516-21.

Hadley, J. and J.M. Mitchell. 1997. “Effects of HMO Market Penetration on Physicians' Work Effort and Satisfaction." Health Affairs (Millwood) 16(6): 99-111.

Hadley, J. and J.M. Mitchell. 2002. "The Growth of Managed Care and Changes in Physicians' Incomes, Autonomy, and Satisfaction, 1991-1997." International Journal of Health Care Finance and Economics 2(1): 37-50.

Keeton, K., D.E. Fenner, T.R. Johnson and R.A. Hayward. 2007. "Predictors of Physician Career Satisfaction, Work-Life Balance, and Burnout." Obstetrics and Gynecology 109(4): 949-55.

Kerse, N., S. Buetow, A.G. Mainous 3rd, G. Young, G. Coster and B. Arroll. 2004."PhysicianPatient Relationship and Medication Compliance: Primary Care Investigation." Annals of Family Medicine 2(5): 455-61. 
Landon, B.E., J. Reschovsky and D. Blumenthal. 2003. “Changes in Career Satisfaction among Primary Care and Specialist Physicians, 1997-2001." Journal of the American Medical Association 289(4): 442-49.

Leigh, J.P., R.L. Kravitz, M. Schembri, S.J. Samuels and S. Mobley. 2002. "Physician Career Satisfaction across Specialties." Archives of Internal Medicine 162(14): 1577-84.

Linzer, M., T.R. Konrad, J. Douglas, J.E. McMurray, D.E. Pathman, E.S. Williams, M.D. Schwartz, M. Gerrity, W. Scheckler, J. Bigby and E. Rhodes. 2000. "Managed Care, Time Pressure, and Physician Job Satisfaction: Results from the Physician Worklife Study". Journal of General Internal Medicine 15(7): 441-50.

MacKean, P. and C. Gutkin. 2003."Fewer Medical Students Selecting Family Medicine. Can Family Practice Survive?" Canadian Family Physician 49: 408-9, 415-17.

Martin, S. 1999.“'Is Everyone as Tired as I Am?’ The CMA's Physician Survey Results, 1999.” Canadian Medical Association Journal 161(8): 1020-21.

Pathman, D.E., T.R. Konrad, E.S. Williams, W.E. Scheckler, M. Linzer and J. Douglas. 2002. "Physician Job Satisfaction, Dissatisfaction, and Turnover." Journal of Family Practice 51(7): 593.

Pathman, D.E., E.S. Williams and T.R. Konrad. 1996. "Rural Physician Satisfaction: Its Sources and Relationship to Retention." Journal of Rural Health 12(5): 366-77.

Rivet, C., B. Ryan and M. Stewart. 2007. "Is There an Association between Doing Procedures and Job Satisfaction?” Canadian Family Physician 53: 92-93.

Statacorp. 2007. Stata Statistical Software: Release 10.0 (Version 10.0). College Station, TX: Stata Corporation.

Stoddard, J.J., J.L. Hargraves, M. Reed and A. Vratil. 2001. "Managed Care, Professional Autonomy and Income: Effects on Physician Career Satisfaction." Journal of General Internal Medicine 16(10): 675-84.

Thommasen, H.V., I. Connelly, M. Lavanchy, J. Berkowitz and S. Grzybowski. 2001. "Short Report: Burnout, Depression and Moving Away. How Are They Related?" Canadian Family Physician 47: 747-49.

Townsley, C.A., K. Naidoo, G.R. Pond, W. Melnick, S.E. Straus and L.L. Siu. 2003. "Are Older Cancer Patients Being Referred to Oncologists? A Mail Questionnaire of Ontario Primary Care Practitioners to Evaluate Their Referral Patterns." Journal of Clinical Oncology 21(24): 4627-35.

Whalley, D., C. Bojke, H. Gravelle and B. Sibbald. 2006. "GP Job Satisfaction in View of Contract Reform: A National Survey." British Journal of General Practice 56(523): 87-92.

Williams, E.S., T.R. Konrad, M. Linzer, J. McMurray, D.E. Pathman, M. Gerrity, M.D. Schwartz, W.E. Scheckler and J. Douglas. 2002."Physician, Practice and Patient Characteristics Related to Primary Care Physician Physical and Mental Health: Results from the Physician Worklife Study." Health Services Research 37(1): 121-43. 